\title{
Contrapuntos en torno al concepto, metodología y enseñanza de la economía: notas críticas para comprender la construcción y transmisión del conocimiento en las ciencias económicas
}

Counterpoints around the concept, methodology and teaching of economics: critical notes to understand the construction and transmission of knowledge on economic sciences

\author{
Isaac Enríquez Pérez \\ Universidad Nacional Autónoma \\ de México, México. \\ E-mail: isaacep@unam.mx
}

Fecha de recepción: 18/03/2016 Fecha de aprobación: 06/07/2016

Palabras clave

- ciencia económica - metodología económica - epistemología neo/positivista

- ideología

- enseñanza de la economía - investigación interdisciplinaria

\section{Resumen}

Sin ánimo de desacreditar o demeritar los esfuerzos realizados en la construcción de la teoría económica, el presente artículo tiene como finalidad desestabilizar la noción del concepto convencional de la economía como ciencia y (de)construirlo hasta trascender a la escasez como objeto de estudio de la misma; así como desentrañar los rasgos y el sentido de la metodología orientada a la construcción del pensamiento científico en las ciencias económicas, con especial énfasis en la epistemología neo/positivista predominante y los paradigmas alternativos al interior de la disciplina. Para cumplir con este propósito es importante recurrir a la historia del pensamiento económico y comprender su accidentada evolución conceptual y epistemológica; al tiempo que se reconoce que la economía no es una ciencia homogénea, aunque sí signada por el predominio de un peculiar enfoque que no solo incide en la academia, sino que también extiende su influencia al diseño de las políticas públicas. En suma, este análisis crítico es una invitación al diálogo entre las ciencias económicas y las ciencias políticas, así como al ejercicio de la interdisciplinariedad en la investigación y la docencia. 


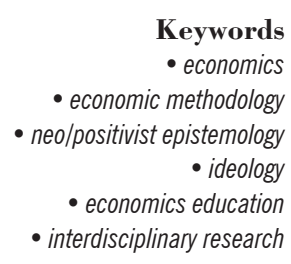

Keywords

methodology

- ideology

- interdisciplinar research

\begin{abstract}
Without wishing to discredit or devalue efforts in building the economic theory, this article aims to destabilize the notion of the concept conventional economics as a science and (de)build it to transcend scarcity as object study of it; and unravel the traits and the sense of building oriented methodology of scientific thought in economics, with special emphasis on neo/positivist epistemology dominant and alternative paradigms within the discipline. For fulfill this purpose is important to turn to the history of economic thought and understanding its rugged conceptual and epistemological evolution; while it is recognizing that the economy is not a homogeneous science, although marked by the predominance of a particular approach that not only affects academia, but also extends its influence to the design of public policies. In sum, this critical analysis is an invitation to dialogue between economics and political science, as well as the exercise of interdisciplinary research and teaching.
\end{abstract}

\section{Introducción}

Una inmensa parte de las actividades humanas y de las relaciones de los individuos en sociedad se orienta a la consecución de los medios de subsistencia requeridos para la satisfacción de las necesidades y aspiraciones bio/psico/sociales, y ello es uno de los fundamentos del sentido de la historia de la humanidad; de ahí que la praxis económica - paralelamente a otras praxis como la religiosa, la científica, la política, la literaria, la simbólico/ cultural - contribuye a la producción y reproducción de la sociedad creando estructuras e instituciones que condensan las decisiones de los actores y agentes socioeconómicos y políticos. Sin embargo, el ejercicio de la praxis económica no es terso, ni armonioso y mucho menos equilibrado, sino que está preñado de contradicciones y conflictos como el desempleo masivo, la informalidad laboral, las crisis económico/financieras, el endeudamiento externo crónico, las espirales inflacionarias, el estancamiento económico, la desigualdad social e internacional, el rezago y dependencia tecnológicos, la pobreza y exclusión social, el desarrollo de algunas naciones y territorios y el subdesarrollo y marginación de la gran mayoría, entre otros. De cara a ello, las teorías económicas que se tornan hegemónicas y que pretenden dar luz -0 , en su caso, tender un manto de encubrimiento - sobre estas contradicciones que socavan los cimientos del mismo capitalismo se configuran sobre la base de una perspectiva metodológica e, incluso, ideológica que es autista y no incorpora en sus análisis y modelizaciones los fenómenos del conflicto, el desequilibrio y la polarización; situación que nos lleva a replantearnos los fundamentos de la noción de la economía como ciencia, así como su objeto de estudio, su metodología y su enseñanza.

Sugerido lo anterior, resulta necesario preguntarnos lo siguiente: ¿qué es la economía como ciencia o campo del conocimiento? ¿Cuál es la 
naturaleza y sentido de su objeto de estudio? ¿Cuáles son los fundamentos epistemológicos de las ciencias económicas? ¿De qué manera incide la ideología en la construcción de la teoría económica? ¿Cuáles son los rasgos de la enseñanza de la economía y cuál es el perfil de la profesión de economista? ¿Cuál es la relación de las ciencias económicas con el conjunto de las ciencias sociales? ¿Cómo podemos construir un diálogo interdisciplinario en esa relación? A partir de estas preguntas, se desagrega el objetivo central presente en nuestra investigación que consistió en reflexionar en torno a la definición convencional del concepto de la economía como disciplina académica, no sin dejar de lado el análisis de las distintas aristas que adquiere la construcción del conocimiento científico en la teoría económica, así como la necesidad de tender los puentes interdisciplinarios entre varios campos del saber con la intención de sentar algunas bases que contribuyan al cultivo del análisis económico más allá de las perspectivas dogmáticas. A grandes trazos, el propósito del presente documento consiste en desentrañar la naturaleza y los rasgos del objeto de estudio de las ciencias económicas, orientando el análisis a la deconstrucción del concepto de la economía como ciencia y de la metodología y epistemología predominante en el ejercicio de la investigación y del proceso de enseñanza/aprendizaje en este campo del conocimiento.

Una premisa que orientó el curso de esta investigación y que bien puede orientar la lectura del presente texto consiste en lo siguiente: el estudio del proceso económico y de las estructuras que le son consustanciales amerita investigaciones de corte interdisciplinario que propicien el diálogo entre las ciencias económicas y el conjunto de las ciencias sociales, enriqueciendo mutuamente sus metodologías, compartiendo conceptos y categorías, y contribuyendo a desentrañar el sentido de un objeto de estudio arraigado en entramados institucionales y en procesos ampliamente relacionados con la praxis política y las relaciones de poder.

\section{De la revisión del concepto convencional de economía a la construcción de una noción de utilidad para las ciencias sociales}

A lo largo de los últimos dos siglos y medio, dos son los rasgos que históricamente definen el perfil y estatus científico de la economía: el primero, asumir como objeto de estudio o campo del conocimiento a la riqueza (con la incorporación sistemática, hacia 1932, del supuesto de la escasez de recursos), y el segundo, adherirse a las pautas metodológicas y epistemológicas de las ciencias físico/naturales en detrimento de la cercanía con el conjunto de las ciencias históricas y sociales (para un panorama amplio sobre este último rasgo véase Enríquez Pérez, 2008b). A su vez, estos rasgos contribuyen a que cada autor y corriente del pensamiento económico construya cierta definición de la noción del concepto de economía como ciencia.

Por ejemplo, en el pensamiento filosófico y social esbozado a lo largo de la Europa precapitalista existió un marcado interés por los orígenes y causas de la riqueza, aunque ello no implicó que se formulasen teorías económicas tal como comenzaron a considerarse a partir del siglo XVIII. Esto es, más que una sistematización del pensamiento económico en la antigüedad europea se abordó el proceso económico de manera, hasta cierto punto, tangencial en la obra de varios filósofos destacados que fueron testigos del esclavismo como modo de producción y de la economía de autoconsumo que regía a las unidades familiares; y, desde la filosofía, el derecho, la ética y la religión pretendieron dar cuenta de temáticas como la propiedad, el cultivo de la tierra, las condiciones de trabajo y los salarios, en el marco de lo que sería la administración del hogar [oikovouía (oikonomía), del oĩkos (oikos)

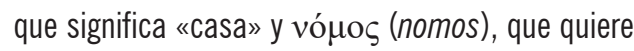
decir «ley»].

Pensadores como Jenofonte (431-354 a. de C.),

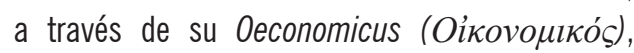
abordan la relevancia de la agricultura y de la 
economía doméstica como fuentes de la riqueza; al tiempo que rescata el diálogo de Socrates (470/469-399 a. de C.) en el cual éste argumenta que la riqueza se relaciona con el bienestar y la prosperidad de la economía doméstica a partir del trabajo duro y la moderación y austeridad en el gasto del hogar (Jenofonte, [362 a. de C. (1993)]. Platón (427-347 a. de C.), en su obra la República, es reticente respecto de la acumulación de la riqueza, el comercio y la usura, aunque le otorga importancia al dinero como medida de valor y como base de comparación entre las cosas que se intercambian [Platón, 380 a. de C. (1986)]. Aristóteles (384-322 a. de C.), por su parte, considera a la riqueza como un medio para mejorar las condiciones de vida de la sociedad y no como un fin en sí misma, de ahí que defina a la economía en dos sentidos: como la ciencia de la administración doméstica y como la ciencia del abastecimiento orientada a la adquisición de bienes a través de su circulación; particularmente, en la Ética Nicomáquea, argumenta que toda actividad humana tiende a lograr algún fin y el de la economía es la riqueza (Aristóteles, [350 a. de C. (1985)]. En estas nociones —esbozadas desde la postura epistemológica del idealismo-, el concepto de necesidad es fundamental e, incluso, con ellas esbozan las bases de una teoría subjetiva del valor.

Por su parte, el pensamiento escolástico principalmente las reflexiones económicas de Santo Tomás de Aquino (1224/1225-1274) — que predominó durante la Edad Media europea y a lo largo del feudalismo que le fue específico y que se caracterizó por el estancamiento económico, postuló — con base en la ética emanada del cristianismo y en un método deductivo y apegado al idealismo - que el proceso económico se juzgaría como un apéndice material de toda conducta humana orientada a la salvación del alma y sujeto a los preceptos de justicia y equidad y a las normas morales y costumbres entonces en boga; de tal manera que las posibilidades de los individuos se reducían a la subsistencia, en tanto que la acumu- lación de riqueza, la usura y la ganancia quedaron sin efecto al ser concebidas como un pecado que impedía la redención espiritual. Especialmente, la Escuela de Salamanca, fundada por Francisco de Vitoria (1483/1486-1546), continúa con las preocupaciones morales en torno a las actividades económicas, con énfasis en la resolución de los conflictos morales mostrados por mercaderes que se beneficiaban de la expansión del naciente imperio español a principios del siglo XVI; de ahí que la equidad y la justicia económica, más que el progreso económico, fuesen su preocupación principal al abordar temas como el comercio internacional, las actividades bancarias, la pobreza, la usura, el dinero y el precio justo.

Hacia los siglos XVIII y XIX —en pleno auge de la expansión del capitalismo y de la forma de vida industrial-, los primeros economistas liberales enfatizaron abiertamente en la riqueza — cuya connotación denotaba felicidad o plenitud- y el progreso económico como objeto de estudio de esta ciencia gestada, al menos en su versión más acabada, en pleno cenit de la modernidad europea. Adam Smith (1723-1790), por un lado y apoyado en el recurso metodológico de la historia económica que combina lo deductivo con lo inductivo, concibió a la economía política clásica como la ciencia del estadista o del legislador que estudia las causas y la naturaleza de la riqueza de las naciones, explicando esta última a partir del trabajo como su principal fuente, la acumulación de capital y la división del trabajo (especialización) como origen de la productividad; para el filósofo escocés el objetivo de la ciencia económica consistía en generar riqueza para el pueblo (crear las condiciones para que los individuos logren, por sí mismos, ingresos abundantes y medios de subsistencia) y para el soberano 0 Estado (dotarlo de rentas para proveer los servicios públicos 0 de interés común) (Smith, 1776). Jean-Baptiste Say (1767-1832), por su parte, argumentó que la economía política tiene como objetivo desentrañar la forma en que se crean, distribuyen y consumen las riquezas. Para David Ricardo (1772-1823), la 
economía política se orienta — tras la adopción plena del método deductivo — a la determinación y estudio de las leyes - en esencia empíricas y universales - que condicionan la distribución de la producción agrícola e industrial entre las clases sociales (propietarios de la tierra, propietarios del capital y trabajadores) que contribuyen a la formación del total producido (Ricardo, 1817). Thomas R. Malthus (1766-1834) señala que la economía política es una ciencia que tiene como fin último la investigación sobre las causas que propician el aumento de la riqueza. En tanto que John Stuart Mill (1806-1873) concibe a esta disciplina desde la perspectiva de una metodología inductiva que sentó las bases de la escuela histórica alemana y del institucionalismo económico, como una ciencia que estudia las leyes — consideradas, en un principio de su pensamiento, como invariables - que moldean aquellos fenómenos sociales relacionados con las acciones coordinadas para la producción y distribución de la riqueza, siempre y cuando dichos fenómenos no sean alterados por otros objetivos sociales (Mill, 1836 y 1844). Estas perspectivas liberales enfatizan en la riqueza como dimensión de un orden natural autorregulado, predecible y en equilibrio a estudiar desde una metodología mecanicista/naturalista que atiende a la producción de bienes materiales (Smith y Malthus) 0 a la distribución (Ricardo y Mill). En suma, en estos autores subyace la idea de que los fenómenos sociales poseen un comportamiento similar a los fenómenos naturales, por lo que postularon una supuesta armonía natural en el sistema económico.

La crítica de la economía política clásica condensada en la obra de Karl Marx (1818-1883), reconociendo el fenómeno de la explotación y los efectos sociales negativos del capitalismo desde el pensamiento dialéctico y el materialismo histórico, distingue entre la economía política clásica —que investigó, desde William Petty, la conexión interna de las relaciones de producción burguesas - y la economía vulgar — que deambula de manera estéril y esboza explicaciones obvias en torno a la conexión aparente de los fenómenos, al tiempo que repite una y otra vez las respuestas ofrecidas en un pasado por la economía científica, tornando en verdades eternas las ideas que la burguesía se forma sobre su propio mundo- (Marx, 1867:99). Por oposición a estas perspectivas, Marx argumentó que la ciencia económica estudia las relaciones sociales de producción, el modo de producción concreto que predomina en una sociedad en cierto momento histórico y sus posibilidades de transformación; esto es, para Marx la economía es la ciencia de la producción en tanto acto histórico y económico. Paralelamente a lo anterior, para Friedrich Engels (1820-1895) la economía política — que comienza por la mercancía, pero que no trata de cosas, sino de las relaciones entre personas y entre clases sociales - es la ciencia que estudia las leyes que rigen la producción, la distribución, la circulación y el consumo — cuyas condiciones no son inmutables - de los medios materiales vitales que satisfacen necesidades humanas (Engels, 1859 y 1878). Para ambos pensadores alemanes, el motor de la historia es la manera en que los individuos y las sociedades satisfacen sus necesidades materiales o producen los medios de subsistencia (Marx y Engels, 1846); más aún, señalan que los individuos son tales y se hacen históricamente a partir de las condiciones materiales de producción o por el modo como producen. Este método de la crítica de la economía política — que aprehende a la realidad como un todo - reconoce como objeto de estudio a la producción (pues en ella se determina el valor y en ella radica la contradicción fundamental del capitalismo: la explotación y la expoliación de la plusvalía) y en interpretarla —a la produccióncomo socialmente determinada en tanto los individuos producen en sociedad y no de manera aislada, oponiéndose con ello al carácter ahistórico que otorgaron a la producción los economistas clásicos. Así, la producción es el punto de partida de la praxis económica y un componente de la totalidad orgánica que sostiene relaciones de interdependencia recíproca con la distribución, el intercambio y el 
consumo. Se trata de concepciones de la economía que enfatizan en la lógica contradictoria del capitalismo y en el carácter histórico de la necesidad desde el pensamiento dialéctico.

Con la revolución marginalista, William Stanley Jevons (1835-1882) definió a la economía (economics) —desde una perspectiva hedonista y apegada a la microeconomía - como un cálculo del placer y del dolor, como una matemática capaz de calcular las causas y efectos de la actividad humana (Jevons, 1871). Por otro lado, tratando de acercar los intereses de la economía política clásica (los condiciones materiales del progreso y el bienestar) y de las teorías marginalistas (los gustos y preferencias), Alfred Marshall (1842-1924) consolida a la teoría económica neoclásica y concibe a la economía como la ciencia que estudia la riqueza y la conducta de la vida cotidiana de la humanidad; 0 bien, analiza aquella parte de la acción individual y social relacionada con la obtención y el uso de la renta y los requisitos materiales del bienestar (Marshall, 1890:17). Siguiendo esta misma orientación, Arthur Cecil Pigou (1877-1959) argumenta que la economía es una ciencia que estudia el bienestar en términos materiales y por su relación con las medidas monetarias (Pigou, 1920).

Hacia 1932, en el contexto del predominio experimentado por la teoría económica neoclásica desde finales del siglo XIX y que para esos años tendió a declinar y a ser cuestionada por los hechos, Lord Lionel Robbins (1898-1984) —apoyado en los fundamentos de la escuela austriaca de economía y, particularmente, de Ludwig von Mises (18811973) - estandariza una definición de la ciencia económica que se generaliza hasta la actualidad en la gran cantidad de manuales y libros de texto introductorios al conocimiento básico de la economía (véase, por ejemplo, Samuelson y Nordhaus, 1985; Fischer, Dornbusch y Schmalensee, 1987; Mankiw, 2011; Graue Russek, 2009; Zamora, 1953; Mochón Morcillo, 2006; Krugman, Wells and Graddy, 2011; y un largo etcétera). Esta definición convencional versa así: «la economía es la ciencia que estudia el comportamiento humano como una relación entre medios y fines escasos, susceptibles de usos alternativos» (Robbins, 1932:15). Con ello, la escasez, la elección, la utilización óptima y el costo de oportunidad son entronizados como las principales dimensiones del objeto de estudio de la ciencia económica. Si bien, casi medio siglo después el mismo Robbins vuelve a la carga y reconceptualiza el objeto de estudio de la economía refiriéndose a aquellas actividades e instituciones gestadas por la escasez (1981:191); con ello supedita la vida social a la escasez, al tiempo que omite las circunstancias históricas. Se trata de una definición que enfatiza en la escasez desde una perspectiva estática y objetivista.

Por su parte, John Maynard Keynes (1883-1946) planteó que la economía consiste en un método más que en una doctrina; en una técnica de pensamiento 0 un aparato mental que contribuye a esbozar conclusiones correctas en torno a problemas económicos agregados -y no precisamente microeconómicos - que es necesario resolver con dichas herramientas y mediante la intervención. En el contexto de la Gran Depresión de los años treinta, el principal problema económico para este economista británico no era la hipótesis de la escasez y la elección, sino el desempleo, la necesidad y el uso de recursos laborales abundantes en estado ocioso con la finalidad de procurar el pleno empleo (Keynes, 1931).

En 1948, con el objetivo de conciliar la teoría económica neoclásica con los supuestos de la teoría keynesiana, Paul Anthony Samuelson (1915-2009), desde la perspectiva del descriptivismo, generalizó otra noción en la enseñanza de la teoría económica, a saber: la economía es el estudio de la manera en que las sociedades utilizan con eficiencia los recursos escasos para producir bienes valiosos y distribuirlos entre diferentes individuos (Samuelson y Nordhaus, 2006:4). De ahí que la contribución fundamental de la teoría económica consiste en reconocer primeramente la escasez y posteriormente las formas para que la sociedad realice 
un uso eficiente de los recursos escasos (6). Se trata de una concepción que enfatiza en la fase de intercambio y los hechos económicos se reducen a relaciones en las cuales los individuos compran, venden, negocian, invierten y convencen (5), así como en el análisis del comportamiento administrativo y gestor de los individuos y las colectividades (los individuos extendiendo sus ingresos limitados, la eficiencia en el uso de los recursos, las empresas y el costo de la mano de obra, los impuestos y el gasto del gobierno, las ganancias derivadas del comercio internacional, la reducción de la inflación, la gestión de los fondos de inversión, las licencias para emisiones de contaminantes, etc.).

A principios de la segunda mitad del siglo XX, Milton Friedman (1912-2006) distinguió entre economía positiva y economía normativa. Mientras esta última se refería al deber ser y a los valores que subyacen a la forma en que debería funcionar el proceso económico, la primera —a decir de Friedman (1953) — remite a una ciencia objetiva similar a la física capaz de estudiar lo que es, independiente de juicios valorativos y que genera un sistema de generalizaciones experimentales para el análisis y predicción correcta de los hechos económicos y de las consecuencias de los cambios en las circunstancias que les envuelven.

Fueron la definición de Robbins — con las correspondientes adecuaciones introducidas en los futuros manuales de economía- y la metodología desprendida de la obra de Friedman las que delinearon los senderos de la corriente principal (mainstream) de la teoría económica, tanto en lo relativo a la construcción de nuevos conocimientos (investigación) y al proceso de enseñanza/aprendizaje como en el ejercicio profesional orientado al diseño y adopción de políticas públicas.

Ante esto cabe preguntarse lo siguiente: iexiste un mundo con escasez? ¿Quién (o qué actores y agentes socioeconómicos y políticos concretos) determina(n) que un recurso sea escaso, cuáles factores de la producción lo son, y para qué 0 con qué hidden goals 0 intereses creados los definen como limitados o escasos? ¿Todos los recursos, en estricto y absoluto sentido, son escasos? ¿Acaso la producción no es suficiente para satisfacer las necesidades elementales 0 básicas de la población? Una posible primera respuesta —además de las que pudo brindar el propio Robbins - proviene de la misma teoría económica convencional al sostener, un tanto cuanto de manera desacertada, que no existe un paraíso de abundancia, ni un mundo sin escasez, ni mucho menos la utopía de lo ilimitado; si ambos existieran entonces los bienes y servicios serían gratuitos (precio igual a cero como en los casos de la arena del desierto y el agua de mar; ejemplos nada afortunados para referirse al sentido de las relaciones sociales propias del proceso económico), los mercados no serían necesarios y la ciencia económica carecería de toda relevancia e interés. Como ese mundo no existe, resulta preciso proceder con eficiencia haciendo el mejor uso de los recursos escasos (Samuelson y Nordhaus, 2006:4). Específicamente, la noción de Robbins, que enfatiza en la utilización óptima de recursos escasos ante fines ilimitados que pueden sortearse con usos alternativos, termina por supeditar la ciencia económica a una dimensión microeconómica que hace de esta disciplina una mera técnica administrativa para la acción racional desde una perspectiva instrumental y para la gestión de la supuesta escasez. Ahondando más en la reflexión, cabe destacar que ciertos factores de la producción esenciales como la fuerza de trabajo (las crisis de desempleo y la destrucción de puestos de trabajo lo evidencian), el conocimiento 0 el residuo tecnológico, la organización empresarial y energías alternativas como la solar 0 la eólica no son escasos; por el contrario, suelen ser abundantes e, incluso, ilimitados y subutilizados. En principio, si existe la escasez es porque alguien o algunos individuos u organizaciones estipulan que ciertos recursos 0 factores de la producción sean concebidos como limitados o restringidos, y ello en sí supone relaciones de poder y el principio de la propiedad privada en esa decisión y propensión a la concentración, dilapidación o infrautilización de dichos factores. 
Detrás de esta definición convencional y generalizada está encubierto el principal y contradictorio problema del proceso económico y que justo polariza históricamente al pensamiento económico, a saber: la distribución de la riqueza y los arreglos políticos que le subyacen a partir de la correlación de fuerzas y de poder que lo configuran. Pensar en la escasez es evadir y subsumir el problema de la transformación social y la construcción de alternativas, es preservar - a contracorriente de los hechos - el status quo, legitimar el régimen de propiedad privada y perpetuar las desigualdades e injusticias propias de las relaciones de poder consustanciales a la construcción de mercados, movidas por el afán de lucro y supuestamente reguladas por la intersección de las curvas de la oferta y la demanda y por el ajuste del sistema de precios; es, ante todo, una argucia ideológica para invisibilizar, normalizar e institucionalizar la estratificación social propia del capitalismo. En el fondo de todo ello está el problema de la intervención del Estado 0, mejor dicho, del tipo de intervención 0 acción colectiva que puede perfilarse en el proceso económico desde el sector público. A grandes rasgos, si se asume como dada la existencia de la escasez, tiende a justificarse la estratificación, la inequidad y las desigualdades, pues como se arguye una carencia 0 insuficiencia de recursos, entonces la desigualdad y la pobreza son entendibles, «naturales» y algo dado de una vez y para siempre.

A decir de Samuelson y Nordhaus (2006) y de N. Gregory Mankiw (2011), la escasez remite a una situación en la cual los bienes son limitados en relación con los deseos infinitos. ¿Acaso saciarse el hambre, arroparse el cuerpo, procurarse un techo, formarse y capacitarse, acceder a un empleo, gozar del esparcimiento, son deseos infinitos? Tan sólo en México, a decir de la Asociación Mexicana de Bancos de Alimentos (AMBA), hacia el 2014, 30 mil toneladas de alimentos (granos, carnes, verduras, frutas) se desperdician al día, y al año algo así como 10 millones de toneladas; en tanto que a nivel mundial esas cifras se elevan a un millón
300 mil toneladas desechadas diariamente. Por su parte, la FAO, hacia 1998, señalaba que el $10 \%$ del gasto armamentista bastaría para acabar con el hambre en el mundo; mientras que el Instituto Internacional de Estocolmo para la Investigación de la Paz calculó que entre 1988 y 2013 se gastaron 34 billones de dólares en gasto militar, cifra que bastaría para terminar con el hambre mundial cerca de 771 veces. Si acaso la escasez y la elección serán un aspecto de los gobiernos nacionales asediados por la deuda, obsesionados por la estabilidad macroeconómica, y corroídos por la corrupción y la evasión fiscal; de aquellos ministros de hacienda y economía o de gobernadores de bancos centrales que - convencidos de las bondades de las políticas deflacionarias y el estancamiento estabilizador - se enfrentan a la falsa disyuntiva de controlar la inflación o estimular el crecimiento económico (crear empleos) y salvar enfermos en los hospitales públicos; del estilo de vida de las clases medias — seducidas por el afán de la sociedad de consumo masivo y la civilización del desperdicioy de las clases empobrecidas —asediadas por la exclusión social, la marginalización y la cultura del descarte - que se muerden las uñas y se truenan los dedos para llegar a fin de mes en sus gastos individuales y familiares, y que -en el caso de las masas pobres - se enfrentan a dilemas como el elegir entre medianamente alimentarse 0 adquirir el boleto del transporte público para viajar varios kilómetros con el fin de acceder a la escuela y a los servicios educativos; sin embargo, esta privación no es provocada por una situación dada, ni espontanea, ni por el azar; es, ante todo, una construcción sociohistórica, una cierta manera de organizar las relaciones sociales. Al menos, resulta preciso evitar la tentación de extrapolar sin más, hacia la macroeconomía, el análisis económico agregado de las decisiones individuales, 0 hacia falsas disyuntivas como el apostar por la inflación 0 el desempleo 0 bien por el crecimiento económico (eficiencia) 0 el bienestar social (equidad), un supuesto restringido como el de la escasez que puede ser válido 
en ciertos hechos microeconómicos y escenarios muy acotados donde los actores y agentes toman decisiones entre dos alternativas u opciones, pues no todo hecho económico ni toda relación social funciona como la disyuntiva a la que se enfrenta un muchacho en edad universitaria y ante la cual tiene que decidir — sopesando los costos y beneficios - entre asistir a la universidad o emplearse en alguna actividad remunerada, 0 entre dedicar más horas de estudio a la asignatura de economía 0 al curso de psicología, asumiendo que en esas decisiones se renuncia siempre a algo. Estos ejemplos (por no mencionar que el análisis neoclásico de la economía mundial parte del supuesto de dos países que sólo producen y comercian dos bienes o servicios), propios del individualismo metodológico donde el comportamiento de una sociedad funciona de manera igual o parecida que las decisiones relativas a una casa, a la administración personal del tiempo, a la falsa disyuntiva de un Ministro de Defensa que -movido por intereses creados del complejo militar/industrial - valora incentivar la producción de mantequilla 0 de cañones, 0 al proceder de un conductor de automóvil respecto del uso 0 no del cinturón de seguridad, son todos ellos recurrentes en libros de texto introductorios como los de Samuelson y Mankiw (n. 1958). ${ }^{1}$

Más todavía: cabe mencionar que la estratificación de las sociedades no funciona ni se estructura a partir de la escasez, sino que es consecuencia histórica de la creación de excedente o de la abundancia que, al ser apropiados de manera privada, conduce a la jerarquización de las colectividades humanas y distribuye — de manera desigual 0 inequitativadicho excedente, no con el objetivo de lograr la satisfacción de las necesidades vitales propias de la reproducción bio/psico/social de la fuerza de trabajo, sino con la abierta finalidad de acrecentar y acentuar el estatus privilegiado de los estratos sociales minoritarios que detentan alguna modalidad y dosis de poder político, empresarial 0 simbólico. Las dispa- ridades y el conjunto del sistema de estratificación configuran y le brindan cauce a la abundancia, mas no a la escasez, y lo hacen mediante la correlación de fuerzas en la construcción de los mecanismos de poder y el reparto de la propiedad, así como a través de la instauración e institucionalización de la violencia, la perpetuación de la desigualdad social e internacional y la diferenciación en clases sociales y en territorios desarrollados 0 subdesarrollados.

Más aún, no toda acción social se orienta a maximizar u optimizar los recursos (a economizar), ni toda decisión 0 acción de los individuos históricamente determinados responde al supuesto de que dadas sus restricciones optimizan sus alternativas u opciones, minimizan riesgos e incertidumbre, y utilizan con eficiencia los recursos empleando el mínimo posible de estos. La noción de Robbins parte del supuesto de la existencia de mercados regidos por la competencia perfecta, de un homo œconomicus dotado de una racionalidad maximizadora e ilimitada y de información también perfecta, pero carente — dicho individuo inexistente - de referencia histórica; paralelamente, deja sin aclarar los fines a alcanzar con los recursos usados, fines que — por supuestoimplican un posicionamiento ideológico, ético y normativo que es omitido por Robbins en su definición al pretender la neutralidad de la ciencia económica. ¿Qué es lo óptimo? ¿Cómo definirlo o determinarlo y a partir de qué elementos? ¿Con respecto a qué cosa o fenómeno algo es óptimo? son preguntas obviadas en esa definición convencional y encubiertas por el carácter maximizador del individuo y su afán de lucro y ganancia.

Luego de este sucinto y apretado recorrido por la historia del análisis económico, nos aproximamos a lo que consideramos la construcción de una noción del concepto de economía con la cual esta disciplina pueda relacionarse de manera más estrecha con el conjunto de las ciencias sociales y con los referentes filosóficos de la construcción del conocimiento. 
La economía es una ciencia social y política que estudia el sentido de las decisiones tomadas por los individuos y colectividades respecto de las formas históricas y específicas de organización que las sociedades adoptan para configurar y encauzar —en el contexto de asimétricas, estatificadas y conflictivas relaciones de poder- las instituciones y estructuras que remiten —en una lógica circular y sistémica - a la extracción, producción, intercambio distribución y consumo de insumos, bienes y servicios (los medios materiales para la supervivencia y la reproducción y perpetuación social y temporal de la vida) con el objetivo de procurar la satisfacción de las necesidades, sentimientos y aspiraciones bio/psico/societales.

Decimos que la economía es una ciencia social y política $-\mathrm{y}$, por tanto, una ciencia factualporque la praxis económica o el proceso económico en su conjunto es un fenómeno social dotado de un carácter histórico en el cual los individuos, en constante interacción, toman decisiones y despliegan su acción en el contexto de organizaciones que condensan y a la vez —en su intergénesis con el individuo - configuran estructuras sociales dotadas de pautas de comportamiento, simbolismos, reglas, valores, instituciones y relaciones de poder construidas históricamente; de tal modo que los fenómenos o hechos económicos no se presentan de manera espontánea, aleatoria, fortuita 0 casual, y tampoco devienen en apariencias ante los recursos de observación, medición y contrastación empírica del sujeto investigador, sino que se presentan entreverados y articulados con distintas esferas de la realidad social —dimensión territorial, jurídica, política y simbólico/ideológico/cognitivo/cultural— que les condicionan recíprocamente en su naturaleza y comportamiento; de ahí que se precise desentrañar su intergénesis o las (inter)causalidades, correlaciones e interconexiones que le dan sentido al mundo fenoménico relativo a la praxis económica que es parte de una totalidad históricamente cambiante, conflictiva y sistémica u orgánica como lo es el conjunto de la realidad social 0 de las sociedades humanas regidas por un movimiento continuo o constante. Más aún, el proceso económico no sólo posee dimensiones materiales, sino que ante todo es una construcción sociocultural e institucional que supone la edificación de una civilización para inspirar y arraigar discursos, símbolos y pautas de comportamiento relacionados con la construcción de mercados y la producción y circulación de los medios de vida en tanto configuraciones históricas, así como con el sentido y la posición que adquiere la acción social de los individuos y sus decisiones en dicho proceso económico y en las amplias relaciones de poder que estandarizan actitudes, instituciones y cursos de acción respecto del circuito necesidad/ producción/trabajo/satisfacción. En este contexto, el mercado es una construcción histórica, es una relación social, pero — a su vez — es una estructura institucional que condiciona y brinda referencia a la acción social de los individuos y a los caminos que adoptan sus organizaciones; esta estructura institucional es diferente de un espacio geográfico a otro, de un momento histórico a otro, de ahí que no existan modelos y prácticas universales de mercado y de praxis económica.

No se trata de una ciencia social neutral ni ajena a la ética y a las connotaciones ideológicas y valorativas que esta última puede suponer, pues está abiertamente relacionada y entreverada con las relaciones de poder (con la construcción del poder) y con el diseño y ejercicio de las políticas públicas y las instituciones que esbozan los patrones de comportamiento de los individuos.

A grandes rasgos, si el comportamiento y funcionamiento de los mercados 0 de las estructuras económicas es el objeto de estudio de la economía, resultará pertinente reconocer que el mercado en tanto el espacio físico o virtual en el cual se procura satisfacer las necesidades humanas - es una construcción social, una relación social, que se configura históricamente a partir de las decisiones y convergencia de los individuos y de sus organi- 
zaciones con la finalidad de engarzar el proceso de producción —en tanto punto de partida y de reinicio- con la circulación, intercambio, distribución y consumo de factores de la producción, insumos, bienes y servicios. Así, el mercado es una estructura económica y, más específicamente, una macroestructura institucional que condensa relaciones sociales y de poder, simbolismos y patrones culturales, decisiones individuales, comportamientos organizacionales, así como la circularidad de la cadena necesidad/trabajo/satisfacción; es una estructura social de producción e intercambio de satisfactores de necesidades que supone relaciones de poder legitimadas y condensadas por entramados institucionales como el Estado y sus regulaciones formales, e incluso, por instituciones informales como la corrupción, la impunidad y la economía criminal.

Muy pocos son los mercados que no se encuentran regulados, entretejidos y controlados por el Estado. Algunos son enteramente construcciones del sector público y están condicionados por las políticas públicas que éste estipula; pensemos por ejemplo en la industria aeroespacial en Estados Unidos — dinamizada por las políticas militares y los contratos que otorga el Departamento de Defensa a las empresas privadas - y la Unión Europea — desde el control público directo sobre la propiedad, el capital accionario y las decisiones hasta la formación, en 1999, del consorcio paneuropeo European Aeronautic Defence and Space Company N.V. (EADS) - (véase Enríquez Pérez, 2014); así como en el mercado de la vivienda en Francia durante las décadas de los sesenta y setenta, el cual se configuró en esos años como un mercado burocráticamente construido, controlado por los poderes públicos y dotado de una infraestructura jurídica (derechos de propiedad, control de precios, etc.) y en el cual surgen antagonismos, relaciones de fuerza y alianzas de poder entre las burocracias públicas y el empresariado privado (para un estudio amplio sobre este mercado véase Bourdieu, 2000).

\section{La construcción del conocimiento científico en la economía: el predominio de una metodología neopositivista o hipotético/ deductiva}

Tras analizar las nociones del concepto de economía como campo del saber a lo largo de la historia del análisis económico, privilegiando la reflexión en torno a la definición que mayor difusión y arraigo tiene entre los manuales de introducción a la economía usados en las escuelas de ciencias económicas y empresariales y en aquellas carreras que incluyen en sus planes de estudio cursos de principios o fundamentos de economía, ahora resulta preciso adentrarnos en la manera en que los economistas construyen conocimiento 0 ejercen el oficio de la investigación en torno a sus objetos de estudio.

En principio, cabe mencionar que en la teoría económica hegemónica, desde sus orígenes, predomina una metodología positivista, empírico/ analítica, objetivista e, incluso, naturalista en un inicio. Situación que comienza con Adam Smith, quien —al igual que los pensadores que le fueron contemporáneos - orientó su investigación a desentrañar las «leyes naturales» del orden económico autorregulador representado por la emergencia del capitalismo, sobre la base de la epistemología propia del paradigma newtoniano/cartesiano, con el cual se asumió que los fenómenos sociales poseen un comportamiento similar a los fenómenos naturales; aunque a diferencia de otros, Smith fue capaz de condensar una teoría de la naturaleza humana, una teoría de la historia y una teología natural (doctrina greco/escolástica del derecho natural) y, con ello, concibió a la sociedad como una «máquina económica» dotada de un funcionamiento mecánico, ordenado y predecible que le da sustento a la construcción de certezas y la formulación de leyes generales que regulan el orden social, y en la cual las estructuras son ajenas a la voluntad del sujeto y se rigen por un modelo de equilibrio natural 0 por 
una supuesta armonía natural en el sistema económico (para mayores detalles véase Enríquez Pérez, 2008 a y b). Se afianza con David Ricardo al intentar aproximar y conciliar las leyes empíricas propias de los fenómenos económicos con las leyes analíticas de los fenómenos físicos, pero prescindiendo de la historia económica como recurso de contrastación empírica y subsumiendo la relevancia de los entramados institucionales para privilegiar los factores de la producción y la dimensión estrictamente material del conjunto del proceso económico. Y degenera con la adopción del individualismo metodológico que, en tanto enfoque estático, concibe a la sociedad capitalista como agregación 0 sumatoria de individuos; y con la radicalización del llamado método del instrumentalismo predictivo (sobre este calificativo véase Boland, 1997) de Milton Friedman (1953) que antepone los modelos econométricos al curso de la realidad social.

Además, hacia finales del siglo XIX, con la revolución marginalista y el ascenso de la escuela austriaca de economía, se presentó la transición de la political economy a la economics, así como el énfasis en el estudio de la fase de intercambio; y ello supuso desarraigar el análisis de las contradicciones consustanciales del capitalismo que se suscita en la esfera de la producción - especialmente la existencia de clases sociales, la explotación de la fuerza de trabajo y la expoliación de la plusvalía - y relevar o suplantar el estudio agregado del Estado-nación o de la riqueza de las naciones por el de las preferencias del individuo, dejando de lado con ello el carácter histórico y la dimensión espacial y sociopolítica del proceso económico, de tal modo que el tiempo histórico y el territorio son omitidos y los hechos económicos se conciben como inmutables, eternos y sin referencia a la incertidumbre, lo institucional, a las relaciones de poder y dominación, y a lo específico de las prácticas cotidianas de cada comunidad respecto de la satisfacción de sus necesidades.

En términos del ejercicio del oficio de investigación, la ciencia económica estudia las relaciones causa/efecto propias de los hechos y procesos económicos; y lo hace fundamentalmente mediante una metodología deductiva, aunque históricamente no omite la importancia de la inducción o la combinación de las dos modalidades de construcción de conocimientos - especialmente cuando se trata de la llamada economía aplicada o de la historia económica.

Un componente básico que subyace a la construcción de conocimiento en las ciencias económicas son los supuestos metodológicos que le permiten al economista acercarse a la esencia de la realidad; a partir de ellos, adopta la deducción como estrategia metodológica para abstraer y simplificar los hechos económicos y para alcanzar no la validez sino la utilidad o el ámbito en que será aplicada una teoría 0 modelo económico, y como resultado esboza generalizaciones 0 uniformidades empíricas causales, siempre y cuando las variables consideradas exógenas se asuman constantes 0 inmutables. Sin embargo, el alto nivel de abstracción y la modelización econométrica inhiben las posibilidades de contrastar las proposiciones con el mundo fenoménico. Esto significa que los seguidores de los teóricos marginalistas que llevaron a las últimas consecuencias sus contribuciones apuestan a deducir estas leyes 0 generalizaciones de axiomas radicados en la mente del economista, para proceder a recolectar, sistematizar, procesar y analizar información y datos con la finalidad de validar o refutar los modelos y teorías económicas.

Cabe preguntarse entonces, ¿qué es un supuesto metodológico de la economía? Un supuesto en economía remite a las representaciones generales de la realidad que pueden ayudar a comprenderla con cierta sencillez y facilidad a partir de la abstracción de la esencia o rasgos elementales de los fenómenos y de su comportamiento; se trata de proposiciones, principios o premisas apriorísticas que remiten a creencias de corte metafísico, y su función consiste en sustentar la formulación de hipótesis de trabajo a partir de las generalizaciones empíricas. Así, un supuesto es una excesiva simpli- 
ficación de la realidad que se presenta como irrefutable y que se encuentran implícitos en los modelos económicos que pretenden indicar el impacto de una sola variable sobre otra (por ejemplo, el mecanismo ahorro/inversión en el crecimiento económico). Intenta ser algo parecido a lo que hacen los físicos quienes, para calcular el tiempo que tarda en caer un objeto pequeño como un lápiz desde el último nivel de un rascacielos, comienzan suponiendo que se precipitará en el vacío y sin interferencia alguna; sin embargo, el supuesto se altera al tratarse de la caída de un objeto de mayor tamaño.

Entre los supuestos implícitos en los modelos económicos neoclásicos convencionales y más generalizados que se gestan 0 radicalizan desde finales del siglo XIX y prevalecen hasta la actualidad con sus respectivos refinamientos y adecuaciones para contener los cuestionamientos a sus anomalías, destacan los siguientes: a) la escasez es algo dado en la sociedad y genera disyuntivas que conducen a los individuos a tomar decisiones marginales que les obligarán a renunciar a alguna de las alternativas tomadas (costo de oportunidad); b) el individuo maximizador, egoísta y optimizador (tendencia a la maximización de las utilidades 0 los beneficios y la minimización o reducción de los costos) que actúa aislado toma las mejores decisiones 0 elecciones para dominar y controlar su entorno a través del ejercicio de su trabajo y su capacidad mental; c) este individuo, además de contar con una racionalidad ilimitada, está dotado de información perfecta, simétrica 0 completa Joseph Stiglitz (n. 1943) se esfuerza por centrar la atención en modelos neoclásicos con asimetría de información - y de preferencias estables y flexibles; d) por tanto, los individuos 0 agentes económicos —además de ser optimizadores en el sentido de Pareto- se consideran idénticos 0 iguales entre sí y su conducta se orienta a calcular y elegir en automático la alternativa que maximice sus beneficios; e) las oportunidades le son dadas de manera externa al individuo y no es posible que las altere, pues pesan sobre él ciertas restricciones; f) las elecciones racionales maximizadoras del individuo derivan constante y automáticamente en la eficiencia económica y el bienestar social a partir de la cooperación en el mercado y de la sumatoria del bienestar individual; g) los mercados están regidos por la competencia perfecta, imperfecta o monopolista — como lo descubrió Joan Robinson (19031983) —, según sea el caso del economista que lo suponga; h) el individuo y su conducta se adaptan a un medio cambiante y responde a incentivos generalmente, aunque no sólo, los estipulados por el sistema de precios u otros de tipo monetario-; g) los precios relativos tienden a ajustarse 0 al equilibrio económico tras converger las curvas de la oferta y la demanda; i) el mercado — que, en esencia, se reduce a precios y cantidades, y se encuentra autorregulado-y, especialmente, los precios relativos son el mecanismo que asigna los recursos con eficiencia y equidad, por tanto, es posible prescindir de las intervenciones estatales (postura radical del Laissez-faire); j) las instituciones se asumen como dadas y exógenas al proceso económico y se suponen plenamente aceptadas por los individuos y las sociedades; k) las funciones de producción son continuas y los factores de la producción pueden sustituirse entre sí; I) la presencia de expectativas racionales y adaptativas -incorporación hecha por John F. Muth (1930-2005) y Robert E. Lucas Jr. (n. 1937)_; m) la existencia del pleno empleo; n) la argucia del ceteris paribus, que se asume como indispensable para la abstracción y simplificación de la realidad, y que remite a suponer que en un modelo económico, salvo las variables analizadas, todas las demás permanecerán constantes 0 sin cambios; entre otros.

En principio, cabe comentar que toda construcción teórica necesita seleccionar y abstraer las dimensiones y elementos destacados de la realidad y sustraer aquellos que no se consideran relevantes. Por lo general, los revisados son supuestos rígidos, faltos de realismo y de contrastación empírica, 0 bien arbitrarios y faltos de asidero empírico, pese «al deseo romántico de asumirlos obstinadamente 
como científicos» (Hahn, 1994). Estos supuestos seminales de la teoría económica hegemónica se caracterizan también por tender a minimizar el riesgo y la incertidumbre, asumir a los agentes económicos como si eligiesen en el vacío y sin referentes institucionales. Respecto de la competencia perfecta postulan, de manera reduccionista, que los bienes producidos son perfectamente homogéneos, cuentan estos bienes con el mismo precio, el número de vendedores y compradores es lo suficientemente grande que ninguno de ellos, por cuenta propia, es capaz de modificar los precios de mercado, y además existe libre movilidad de los factores de la producción. Asimismo, enfatizan en la fase de intercambio y no en el conjunto del proceso económico y, menos aún, en la producción como punto de partida. A partir de este conjunto de supuestos, los economistas convencionales, no pocas veces, generalizan y explican a través de premisas infundadas para derivar en conclusiones previamente estipuladas, omitiendo las relaciones sistémicas y estructurales de los fenómenos o hechos económicos. Así pues, en los supuestos de la economía subyace la noción de que los agentes económicos no son pensados como seres humanos en constante interacción sociohistórica, sino como entidades autómatas obsesionadas con el costo/beneficio; además, los economistas suponen las preferencias de los individuos pero no reflexionan sobre sus orígenes 0 causas, y cómo se configuran históricamente. Más aún, se corre el riesgo, tal como lo argumenta Paul Streeten (n. 1917) de que las deducciones hechas sobre la base de modelos artificiales sean equivocadas en sus pretensiones de describir y analizar los hechos económicos (Streeten, 2002).

Al igual que Robbins, Friedman le resta relevancia a los supuestos poco o nada realistas en la validación y la coherencia lógica de las teorías y modelos económicos, pero el líder de la Escuela de Chicago lleva a sus últimas consecuencias el pragmatismo de su metodología. Especialmente, para Friedman —en correspondencia con la filosofía pragmática norteamericana propuesta por William James
(1842-1910) y John Dewey (1859-1952)—, la ciencia es un instrumento para el control de la realidad y la resolución de problemas concretos que son parte de ésta —en este caso, los propios de la política económica_; al tiempo que también asume que la teoría económica no es verdadera ni falsa, sino que es útil y adquiere validez en la medida que exista un consenso en la comunidad científica; y, más que procurar la verificación de las hipótesis a través de la contrastación empírica, se inspira en la epistemología falsacionista de Karl Popper (1902-1994) para privilegiar la refutación 0 falsación. Importan pues las conclusiones derivadas de las teorías, hipótesis y el sistema de generalizaciones, y éstas serán coherentes 0 válidas si son capaces de predecir correctamente los hechos económicos 0 si estas predicciones son acordes 0 coherentes con la experiencia (Friedman, 1953). Sin embargo, si la economía es concebida por Friedman como una ciencia objetiva al estilo de las ciencias físicas y, a la vez, la asume como una ciencia pragmática orientada a la solución de problemas reales a través de la política económica, se gestará allí una contradicción, pues atender el deber ser supone posicionamientos ideológico/ético/políticos ante el ser que se considera problemático; esa incidencia de la ideología en la teoría económica conduce a la construcción de ciertas (y no otras) preguntas de investigación y se estudian ciertos fenómenos y no otros, invisibilizando y encubriendo con ello gran cantidad de facetas de la realidad que le dan forma a los hechos y procesos económicos. Esta faceta ingenieril del economista se afianzó con el nacimiento y auge de la macroeconomía a partir de la década del treinta del siglo XX (al respecto véase Mankiw, 2007).

Para Friedman, explicar (entendido como abstraer, mediante hipótesis que simplifican la realidad, las vertientes y rasgos esenciales de los hechos económicos) y predecir lo desconocido aunque los supuestos carezcan de realismo - en tanto las dos funciones interrelacionadas de la teoría económica 0 de la economía positiva — son simétricas o equi- 
valentes [esta influencia procede de la tesis de la simetría introducida por el movimiento epistemológico del llamado Círculo de Viena encabezado por filósofos como Rudolf Carnap (1891-1970) y 0tto Neurath (1882-1945)]. Con ello, Friedman borra de golpe las críticas a las anomalías 0 inconsistencias de los supuestos y premisas metafísicas que forman el edificio de la teoría económica neoclásica, pues argumentó que no es imprescindible el realismo 0 apego a la realidad de los supuestos, ni tiene cabida el imperativo para que sean realistas; ello en gran medida se debe a que la finalidad última de la teoría económica radica en su capacidad para generar predicciones correctas y coherentes sobre los hechos económicos que aún no son conocidos u observados por el teórico; de ahí que si lo más importante en la teoría económica es la labor de predicción, carecerá de relevancia que los supuestos se tornen distantes de la realidad y que, incluso, la contradigan (Friedman, 1953). Entonces, nos preguntamos, ise abre paso a aceptar que los supuestos sean falaces, meras condiciones especulativas o cuasiteológicas sin asidero en el mundo fenoménico?, y si son falaces ise correrá el riesgo de validar, a contracorriente de las reglas de la lógica, generalizaciones, conclusiones y predicciones también falaces, incorrectas y distantes de la realidad?; más aún, si no es necesario y relevante el realismo 0 validez de los supuestos para llegar a conclusiones válidas en la teoría económica (esa falta de realismo no conduce a predicciones incorrectas o falsas, según Friedman), ipor qué la obsesión de los economistas de defender a capa y espada la presencia y el papel de supuestos infundados en sus modelizaciones? Más pertinente resultará esta pregunta si pensamos en la identidad teórica y profesional que genera entre los economistas adherirse a los supuestos que simplifican la realidad y tratan de representarla de manera general.

A la par de Karl Popper (1934 y 1963) —quien sostiene que una hipótesis puede refutarse, mas no confirmarse 0 comprobarse, mediante la contrasta- ción empírica—, Friedman (1953) señala que toda teoría económica tiene un carácter provisional y está expuesta a cambios y variaciones en el marco del camino progresivo del conocimiento científico; por lo que el economista se enfrenta al dilema de elegir entre teorías 0 hipótesis diferenciadas que ya fueron contrastadas con la experiencia. Para Friedman esta discriminación entre alternativas es arbitraria, aunque sujeta a criterios como la sencillez (se refiere al menor conocimiento inicial para hacer predicciones) y la fertilidad (precisión de las predicciones y vocación para generar futuras líneas de investigación). Más que la veracidad o falsedad de las teorías económicas, para el Premio Nobel la distinción más importante radica entre teorías 0 hipótesis útiles 0 inútiles en el estudio de los problemas concretos y respecto de las demandas que impone la política económica.

En esta forma de construir conocimiento subyace una marcada lógica fragmentaria, mecanicista y de ajuste automático. Por ejemplo, en varias de las teorías del crecimiento económico se hablaba de la necesidad de estimular el mecanismo ahorro/ inversión e inducir el progreso técnico para detonar y profundizar la industrialización que derivaría en la acumulación de capital y en el consecuente crecimiento de las economías nacionales. Al tiempo que impera cierto individualismo metodológico que parte —como objeto del análisis económico — del individuo aislado, en libertad absoluta y movido por sus preferencias y un voluntarismo (solo constreñido por la escasez) orientado a maximizar las utilidades; ello por oposición a la sociedad como una totalidad orgánica e interrelacionada.

Esta metodología hipotético/deductiva muestra una marcada aspiración 0 pretensión de objetividad a partir de la adhesión — con sus respetivos matices - al monismo metodológico. El método científico (por ejemplo en autores como Mankiw, 2011) que pretende la objetividad tiene que conducir al economista a comenzar con la observación de los hechos económicos, recurrir a la teoría - especialmente a los supuestos - que explica lo observado 
y regresar a la observación para darle forma a las teorías y modelos económicos, reconociendo con ello la importancia de los experimentos que aporta la historia económica para sustituir los experimentos de laboratorio empleados por los físicos con el fin de comprobar sus teorías; esto es, se asume que la metodología que parte de agrupar diferentes teorías, recabar datos sobre comportamientos individuales 0 agregados y analizarlos tratando de comprobar 0 refutar sus teorías que tratan de explicar el funcionamiento de la realidad, puede emplearse tanto en el estudio de los hechos económicos como en el estudio de la fuerza de gravedad o la evolución de las especies.

Aunque la teoría económica marginalista introdujo el lenguaje y la notación matemática a la economía para hacer de ella una ciencia parecida 0 que emula a la física y entronizar con ello el estatus y prestigio científico y profesional del economista, fue justamente la perspectiva del descriptivismo propuesta por Paul Samuelson la que afianzó el uso del lenguaje matemático en el análisis económico en aras de alcanzar esta pretendida objetividad. Este Premio Nobel habla de la necesidad de contar con mentes frías al servicio de corazones ardientes para identificar incentivos y analizar costos y beneficios sin idealismo (Samuelson y Nordhaus, 2006:6). La noción que Samuelson tiene del método científico de la economía parte de análisis y planteamientos teóricos para formular generalizaciones; luego, con la observación se recopila información estadística y series históricas, al tiempo que se reconoce la relevancia de la historia económica para el estudio de ciertos fenómenos, por lo que se privilegia el uso de la técnica de la econometría para adaptar las herramientas e instrumentos de la estadística a los hechos económicos y derivar de la masa de datos una serie de relaciones sencillas. Con ello, Samuelson resalta la importancia de la definición de los conceptos, el carácter explícito de los supuestos en los modelos y la demostración de los teoremas (Samuelson, 1947). Además, este economista estadounidense identifica algunas fala- cias que pueden afectar el análisis económico; ellas son la falacia post hoc que remite a la deducción de una relación de causalidad, esto es, si un hecho económico se gestó antes que otro, el primero es, indefectiblemente, la causa del segundo; la falacia de no mantener el resto constante al asilarse una variable para conocer sus efectos en el sistema económico; y la falacia de la composición que consiste en suponer que aquello que es cierto para una parte del sistema económico lo es también para el conjunto del mismo, cuando la totalidad, en realidad, es más que la suma de las partes, 0 bien, el comportamiento del individuo es diferente del comportamiento del agregado del conjunto de la economía (Samuelson y Nordhaus, 2006:5-6).

Con el viraje que supuso la preeminencia del lenguaje matemático en el análisis económico, los modelos econométricos se hicieron explícitos y dejaron de presentarse implícitamente, en tanto que las relaciones se hacen implícitas y no se explicitan, por lo que el empleo de este lenguaje — pese a que se precisa de las abstracciones - no siempre es útil ni apropiado, e incluso puede ser engañoso sobre todo cuando marginan algunas dimensiones del análisis (véase Streeten, 2002). Se pierde entonces el sentido de la formalización matemática como instrumento auxiliar o lenguaje abreviado del análisis económico y no como instrumento de investigación, tal como lo sugerían Alfred Marshall y Arthur Lyon Bowley (1869-1957) (Marshall, 1901), y las pretensiones de precisión de la notación matemática termina por desdibujar los conceptos al intentar u omitir la representación de relaciones sociales específicas, regidas por la incertidumbre y las contradicciones y que no adoptan una lógica lineal o mecanicista. Por si fuera poco, el uso excesivo de los modelos matemáticos construidos a partir de la deducción demerita el estudio del mundo fenoménico y de la contrastación empírica.

El mismo Paul Sreeten señala la carencia de rigor al momento de enunciar las condiciones en las cuales la economía matemática adopta sus modelos, y concluye que en este enfoque de la 
ciencias económicas impera la técnica sobre la esencia, la forma sobre el contenido, la elegancia 0 belleza técnica sobre el realismo y la relevancia; por lo que el lenguaje matemático debe ser servidor de la economía y no su amo. Ello es entendible porque la economía matemática fungió como una vía de escape que evadió a los economistas de la necesidad de criticar el capitalismo de la segunda posguerra, pero a pesar de los instrumentos sofisticados, son pocos sus resultados en la generación de nuevos conocimientos, en el análisis profundo, la configuración de predicciones exactas, y en el planteamiento de prescripciones y políticas económicas; a partir de todo ello, concluye Streeten, que la ciencia económica se torna muy estrecha, endogámica, intolerante, formalista, escapista, autocomplaciente y distante de la realidad, y — por ellosugiere sacrificar precisión matemática en aras de contrarrestar el reduccionismo (Streeten, 2002).

En este contexto, cabe puntualizar también que la ciencia económica selecciona sólo lo que es medible y omite el resto; sólo existe lo que es mensurable y es posible representar a través de la notación matemática; sin embargo, esta postura metodológica ignora 0 torna marginales los temas punzantes y disruptivos de una sociedad que, muchas veces, son de difícil o imposible cuantificación porque escapan a las dimensiones materiales y se arraigan en los intrincados intereses creados que moldean a las instituciones 0 en lo escurridizo de problemas relacionados con la dimensión simbólico/cultural y sus especificidades. Más que la exclusiva finalidad predictiva de la ciencia económica a partir de estos modelos econométricos, y que Friedman le otorga y equipara a la explicación reconociendo que esas predicciones son probabilísticas y cuentan con margen de error amplio en algunos casos (si se hacen predicciones a priori de hechos económicos futuros, resulta posible hacer explicaciones a posteriori de fenómenos pasados proyectando en retrospectiva la predicción), es importante destacar que tiene también dimensiones descriptivo/analíticas, comprensivo/interpretativas, axiológicas, norma- tivas y prescriptivas que se empalman y traslapan, hasta incluso tornarse endebles sus fronteras.

Por si fuera poco y no porque defendamos a ultranza una autonomía o soberanía disciplinaria - pues parte de la esencia de este documento es la necesidad de postular la investigación interdisciplinaria sobre la realidad social-, las pretensiones de la ciencia económica no se limitan a la hegemonía de su metodología y supuestos al interior de sus comunidades científicas, sino que se extienden -en una especie de imperialismo de la economía (término introducido por Boulding, 1969) - a disciplinas como la biología, la psicología social, los estudios jurídicos, la investigación educativa, la historia, la sociología, la ciencia política y la administración pública y los estudios de las relaciones internacionales, que incorporan en sus sistemas conceptuales los supuestos de la maximización o la optimización (la satisfacción máxima de las preferencias del individuo a partir de recursos escasos), y el ejercicio de la racionalidad instrumental 0 el cálculo utilitarista de costo/beneficio. Asumeo que el homo psychologicus, el homo historicus, el homo sociologicus, el animal político o el

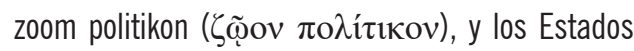
despliegan su acción social y rigen su conducta como el fantasioso e imaginario homo œconomicus que procede asumiendo restricciones, optimizando opciones, minimizando costes y riesgos, y utilizando y administrando con eficiencia los recursos escasos. Gary Stanley Becker (1930-2014) es el ejemplo más destacado de los economistas que extienden este dominio conceptual y metodológico hacia otras ciencias sociales e, incluso, a la biología; ello lo hace argumentando que el análisis económico puede aplicarse al estudio de toda decisión — que por definición es, en sí, económica-y de todo comportamiento humano regidos o condicionados por la escasez, la elección y el costo de oportunidad (Becker, 1976). Esto se observa en perspectivas teóricas como la teoría de juegos, la racional choice, la public choice, la bussines administration, la economía de la caridad en el Tercer 
Sector 0 la administración social del bienestar, la criminología, la educación como forma de inversión, y en la disciplina de la administración pública orientada a la llamada reinvención del gobierno o reforma del sector público.

En suma, la corriente de pensamiento hegemónica de las ciencias económicas cimienta la construcción de teorías y modelos en un único camino 0 posicionamiento como lo es la epistemología positivista/neopositivista e hipotético/deductiva, cuyo objetivo principal consiste en identificar y esbozar generalidades, regularidades, relaciones constantes 0 uniformidades relativas a los hechos económicos y al comportamiento y funcionamiento de los mercados y los agentes económicos sobre la base de modelizaciones que tienden a simplificar la realidad, y a representarla de manera abstracta a través de la formalización matemática y econométrica (economía cuantitativa) o de la axiomatización matemática, y de los argumentos formales que expresan supuestos y deducciones. Sin embargo, la deducción se impone al trabajo empírico (e, incluso, no facilita la contrastación empírica) y las relaciones se asumen como dadas y se mantienen implícitas en dichas modelizaciones. Es de destacar que mediante la abstracción - ejercicio consustancial a toda construcción teórica- se seleccionan 0 discriminan ciertas dimensiones de la realidad y, más todavía, se corre el riesgo de omitir ciertas aristas que caracterizan la complejidad del mundo fenoménico (algunas facetas de la realidad las observa el sujeto investigador y otras no, aunque se encuentren ante su mirada incisiva; es el caso de las relaciones de poder y el sentido del sistema de estratificación para la teoría económica). Esta modalidad de construcción del conocimiento implica también que, tras la incidencia de la ideología, la teoría económica convencional esboza sus explicaciones sobre la base de supuestos predeterminados que le permiten plantear — sin mayor esfuerzo que la medición y no una más amplia contrastación empírica - ciertas conclusiones y deducciones estipuladas a priori en realidades hipotéticas y desco- nocidas. La invisibilización de amplias dimensiones de la realidad se ahonda al acotar los alcances de la ciencia económica a los problemas y temáticas que desde la política económica son concebidos por los tecnócratas como urgentes y atendibles desde la agenda pública.

Esta postura ontología y epistemológica positivista/neopositivista de la teoría económica convencional consiste, como es sabido, en asumir lo siguiente: los hechos económicos son cognoscibles, objetivos, ajenos, distantes, externos e independientes del sujeto investigador que, a decir de posiciones extremas y al menos en el papel, no interactúa con el objeto de estudio; la objetividad es la principal aspiración del conocimiento; la exclusión de los valores y la negación de su influencia en el análisis económico; la comprobación 0 verificación de hipótesis y teorías mediante los datos repetibles que fueron recabados y analizados; de ahí que el conocimiento sea generalizable a múltiples casos; el establecimiento de relaciones lineales causa/ efecto para explicar el funcionamiento de los hechos económicos; la existencia o descubrimiento sólo de lo que es medible con los métodos y técnicas cuantitativos; el análisis económico tiene como propósito la explicación, predicción y control de los hechos y procesos económicos; con el supuesto del ceteris paribus los hechos económicos son sustraídos de su contexto y se analizan de manera aislada; y la realidad económica es estable y, en casos extremos, inmutable, estática y determinada por estructuras externas que se imponen a los agentes económicos.

Como acotación necesaria, cabe destacar que la adopción y síntesis de los razonamientos inductivos —en la obra de John Stuart Mill por ejemplo- 0 la combinación de estos con la metodología deductiva - como en el caso de Adam Smith y Thomas R. Malthus - se presentan en el ámbito de la llamada economía aplicada. Esta rama de la ciencia económica puede rastrearse desde las primeras décadas del siglo XIX, pero alcanza su auge hacia mediados del siglo XX con el despliegue de la pericia ingenieril del economista (respecto del perfil del macroeco- 
nomista como ingeniero véase Mankiw, 2007) y las labores de asesoría o consultoría brindada a los políticos y funcionarios del sector público interventor en el proceso económico y en la procuración de un crecimiento en condiciones de estabilidad. En lo fundamental, esta disciplina denominada economía aplicada se encarga de la contrastación empírica para validar o desechar las predicciones esbozadas en los modelos económicos, esto es, se trata de investigaciones 0 estudios empíricos que se encargan de confrontar los postulados teóricos con el curso de los hechos o procesos económicos sin que ello implique romper sus lazos, sino más bien consolidar la simbiosis entre los postulados teóricos y el análisis económico empírico que remite constantemente a la realidad social (sobre esta noción de la economía aplicada véase Fontela Montes, 1990; Sáez Lozano, 1998).

La perspectiva que concibe a la economía como una ciencia aplicada, y que se fundamenta en la simbiosis entre la metodología deductiva y los razonamientos inductivos, pretende explicar los fenómenos económicos y emprende el análisis económico a partir de la construcción de modelos que son resultado de la minuciosa revisión y evaluación de los supuestos y postulados teóricos, así como del pormenorizado análisis de los datos construidos a partir de la observación de los hechos económicos; tras contrastar estos modelos con la realidad y sus distintos escenarios de comportamiento, esta modalidad de economista define y plantea las predicciones que estarán sujetas a su comparación con los hechos observados, y le otorgarán (o no) validez al modelo para explicar la realidad; a partir de este primer esfuerzo, el economista aplicado será capaz de perfeccionar el modelo del cual partió y —en suma - lo hará cambiando los sistemas de información, examinando los supuestos y los fundamentos teóricos, y ajustando los escenarios de comportamiento de los fenómenos (Fontela Montes, 1990; Sáez Lozano, 1998). Ejemplos de economía aplicada son las obras de John Maynard Keynes relativas a los problemas macroeconómicos, de Colin
Clark (1905-1989) y Morris A. Copeland (18951989) en torno a las cuentas nacionales, Wassily Leontief (1906-1999) y su análisis input-output, y del estructuralismo latinoamericano inaugurado con el pensamiento de Raúl Prebisch (1901-1986). Sin embargo, en varios casos tiende a predominar un enfoque instrumentalista de la economía aplicada que privilegia, tras recurrir al uso de los métodos y técnicas estadísticas y econométricas para la medición de los hechos económicos, la contrastación empírica de las hipótesis esbozadas por la teoría económica pura y racionalista (esta última idea es expuesta en Sáez Lozano, 1998), y —agregaríamos - sin mayor intención, en muchos casos, de construir innovaciones teóricas en materia de conceptos, categorías y supuestos.

Destaca también la escuela histórica alemana de la segunda mitad del siglo XIX, la cual argumentó, en aquella época y desde una perspectiva relativista y orgánica heredera del método de la comparación histórica introducido por Friedrich List (1789-1846), que las teorías —y los supuestos que en ellas subyacen - están sujetas a cambios $y$, por tanto, no son inmutables o eternas ni ajenas a la necesidad de contrastación empírica y mucho menos dotadas de una validez universal, pues están expuestas a las circunstancias de cada momento histórico y a las condiciones de cada espacio geográfico. Otra alternativa metodológica es la ofrecida por los orígenes del institucionalismo económico que — desde finales del siglo XIX y a través de pensadores como Max Weber (1864-1920), Thorstein Veblen (1857-1929), Joseph A. Schumpeter (1883-1950), Herbert A. Simon (1916-2001) y Karl Polanyi (1886-1964) quien desde la historia económica reflexionó sobre la utopía del mercado autorregulado - cuestionó el énfasis en la abstracción y el racionalismo defendidos por lo que ya se perfiló como la teoría económica neoclásica, y antepone una perspectiva sociohistórica y evolucionista para el estudio de los hechos y procesos económicos bajo el supuesto de que las instituciones cambian y se adaptan al contexto histórico (sobre este enfoque 
véase Ayala Espino, 1999). Ambas perspectivas teóricas recurren a la inducción como metodología y construyen las predicciones a partir de la observación de generalizaciones o regularidades derivadas del curso de los hechos o procesos económicos.

La alternativa epistemológica que se aleja radicalmente de la perspectiva hegemónica en la construcción del análisis económico es la emanada de la teoría social crítica de orientación marxista, aunque cabe mencionar que su empleo no es generalizado ni masivo entre quienes realizan investigación económica. El principal supuesto epistemológico de esta teoría crítica consiste en asumir que los seres humanos hacen la historia (praxis) y al hacerla se hacen y rehacen así mismos; por tanto, el sujeto investigador no es ajeno a la realidad social que se construye como objeto de estudio, y al conocerla no sólo la aprehende y representa conceptualmente sino que también cuenta con la posibilidad de incidir en ella para transformarla (el conocimiento como praxis que implica valores).

La teoría social crítica enfatiza en el estudio del cambio social y las contradicciones del capitalismo desde el pensamiento dialéctico (la historia es vista como un conjunto de procesos) y la concepción materialista del mundo (la primera determinación es la producción de los medios de subsistencia). Esta perspectiva parte de la idea de que la sociedad es una totalidad orgánica dotada de intervinculaciones y entrelazamientos internos - que se encuentra en movimiento constante y experimenta contradicciones que, al superarse, pueden devenir en su cambio; además, a diferencia del individualismo metodológico, la teoría social crítica postula que el individuo no produce de manera aislada, sino que la producción está socialmente determinada; sin embargo y específicamente para Karl Marx, el objetivo de la teoría consiste en descubrir las tendencias de carácter histórico que asume el proceso económico, es decir, desentrañar las especificidades 0 las relaciones históricas específicas, e identificar la forma social determinada que muestra un proceso en una cierta época inscrita en una evolución histórica más amplia. Para Marx, el análisis económico y de la sociedad en general inicia con el descubrimiento de esas relaciones históricas derivado del ejercicio de la observación, por lo que al privilegiar los hechos y las teorías validadas le resta relevancia a los principios metafísicos; de ahí que su metodología se corresponde con la concepción que define al proceso económico como esencialmente contradictorio y asimétrico. En esencia, para esta metodología económica el proceso económico, lo real, es una premisa en la representación conceptual del mundo fenoménico, al tiempo que entre ambos (el proceso económico y el análisis económico) existe una estrecha y permanente interacción; por ello, el pensamiento abstracto es indispensable para comprender los procesos históricos, sin que entre ellos se geste una plena correspondencia. Marx llega a la conclusión de que el método que consiste en «elevarse de lo abstracto a lo concreto» es el camino más adecuado para apropiarse de la realidad (Marx, 1857), pues lo concreto es concreto porque es la síntesis de múltiples determinaciones, es la unidad de lo diverso; por tanto, al pensamiento se le concibe como un proceso de síntesis tras iniciar con la reconstrucción por etapas de lo concreto a partir de sus determinaciones abstractas más elementales. Detallando esto último: en la teoría del valor se inicia por la mercancía en su forma simple y, posteriormente, se analiza su forma lógica e históricamente secundaria (la mercancía producida en el capitalismo); con ello, el ejercicio de abstracción que procede de lo simple a lo complejo muestra correspondencia con el proceso histórico real. De ahí que el objetivo del análisis económico, para Marx, radique en desentrañar las leyes históricas de las relaciones de producción desplegadas en un momento histórico específico; además, a diferencia de los supuestos propios de la teoría económica neoclásica, Marx considera que las categorías abstractas, pese a su validez respecto de todas las épocas, son construidas a 
partir de ciertas condiciones históricas específicas -y agregaríamos hoy en día, geográficas y culturales - y alcanzan la plena validez sólo para estas condiciones y dentro de sus límites (para mayores detalles sobre esta orientación metodológica véase Enríquez Pérez, 2008b). Autores y teorías representativos de esta metodología económica durante las últimas siete décadas son los trabajos de Oskar R. Lange (1904-1965), los aportes teóricos para el estudio del capitalismo realizados por Maurice H. Dobb (1900-1976), Ernest E. Mandel (1923-1995), Paul A. Baran (1910-1964) y Paul M. Sweezy (1910-2004), la vertiente de la teoría de la dependencia expresada en la obra de Ruy Mauro Marini (1932-1997), el análisis marxista de la economía mundial propuesto por Gill (1996) y Arrizabalo Montoro (2014), y, en parte, la escuela francesa de la teoría económica de regulación.

En general, si bien el análisis económico neoclásico es el hegemónico, la economía no es una ciencia homogénea, sino que a su interior varios enfoques teóricos se disputan la explicación de la realidad, e incluso al interior de cada enfoque teórico existen discrepancias. Estas diferencias marcadas no sólo se relacionan con la modalidad de metodología económica 0 las técnicas e instrumentos de investigación empleados, con los sistemas conceptuales o las premisas, 0 con aquellas dimensiones de la realidad económica que se privilegian en el estudio y las que se descartan u omiten, sino también con los supuestos éticos, axiológicos e ideológicos implícitos en el pensamiento del economista; $y$, si bien podría pensarse que esta diversidad teórica y de juicios de valor representa un hándicap para la economía y para las ciencias sociales en general, más bien se traduce en una de las mayores riquezas y fortalezas del conocimiento sobre lo social humano.

Aunque existe un esfuerzo por defender una artificial división entre economía positiva (descriptiva) y economía normativa (prescriptiva) en aras de asumirse como una ciencia que busca la objetividad, lo que se presenta es una situación en la cual la misma forma de pensar y aprehender la realidad se entremezcla 0 articula con los valores, las prenociones y la ideología del sujeto investigador hasta tornarse indisolubles y conducir al planteamiento de disyuntivas. Una de estas disyuntivas -la cual, por cierto, asumimos como falsa - que recorre la historia del pensamiento económico es la relativa al papel del Estado en el proceso económico y que tiende a polarizar a los economistas en torno a preguntas como imás mercado 0 más Estado? 0 imás libertad del individuo en el mercado y menos intervención pública? o iproteccionismo 0 irrestricta apertura comercial? Buena parte de la producción teórica se orienta a deliberar en torno a estos valores y arreglos institucionales e, incluso, puede ocurrir que el mismo elemento ideológico del sujeto investigador recurra a ciertos conceptos, categorías, supuestos, métodos, técnicas e instrumentos de análisis y no a otros que se inscriben en una perspectiva epistemología y política distinta. Esto es, la dimensión descriptiva del conocimiento respecto de cómo es la realidad social y que deriva del análisis de los datos y series históricas para confirmar 0 rechazar los enunciados positivos, se empalma 0 traslapa con la dimensión prescriptiva y valorativa relacionada con el deber ser respecto de dicha realidad y que también precisa de datos para sustentarse y ejercer la vocación de resolver problemas económicos concretos. De ahí que la teoría no sea neutral pues influye -0 , al menos, pretende influir — directa, indirectamente 0 incluso de manera marginal en la configuración de la agenda pública y en el ejercicio de las políticas públicas, y ello ocurre aunque sus concepciones teóricas 0 recomendaciones de política sean erróneas o poco atendidas por los políticos y funcionarios públicos en el marco del juego de intereses creados imbuidos en el proceso de planeación (excelentes reflexiones sobre el papel de la ideología en la construcción de la teoría económica pueden consultarse en Schumpeter, 1954, y Dobb, 1973; sobre el macroeconomista como científico y como ingeniero véase Mankin, 2007). 
4. La enseñanza de la economía en las universidades y el perfil profesional del economista: la prevalencia de la técnica y la especialización

A la par del auge de la llamada revolución keynesiana, en la década del cuarenta del siglo XX se suscita una revolución pedagógica relacionada con los libros de texto usados en la enseñanza de la teoría económica en las universidades. En ello, desempeñó un papel importante Paul A. Samuelson, quien combinó las destrezas técnicas (el manejo de instrumentos para el análisis económico), la contribución teórica y la pasión por la enseñanza de la teoría económica principal para - tras potenciar el sentido común - formar ciudadanos ilustrados con base en el análisis riguroso de la lógica de las proposiciones económicas y la evaluación de las consecuencias derivadas de su aplicación política, al tiempo que esa cultura ciudadana contrarresta el populismo de los políticos y contribuye a formar parte de las decisiones políticas y a que los representantes procedan con sensatez (Cue Mancera, 2003). Con su manual titulado Economics: an introductory analysis publicado en 1948, Samuelson aportó —usando un lenguaje coloquial que suaviza la extrema formalización matemática de las ideas económicas - cuantiosos ejemplos didácticos de contenido numérico, gráfico o diagramático, e hizo fructíferos esfuerzos pedagógicos para contrastar los capítulos del libro con los comentarios de los estudiantes y de otros docentes. El mayor aporte de esta obra consistió en conjuntar (en la llamada síntesis neoclásica de Samuelson) los aportes de la microeconomía respecto del llamado modelo del equilibrio general con la perspectiva de la determinación del ingreso nacional y el análisis de los agregados económicos, lo cual comenzó a perfilar el campo de la macroeconomía. Con el paso de las décadas, el Economics de Samuelson se enfrentó a una intensa competencia - como lo anotamos en otro apartado - respecto de la gran cantidad de manuales introductorios que pretenden definir la noción del concepto de la economía como ciencia, aunque ese conjunto de libros de texto es muy similar en cuanto a las temáticas abordadas, la estructura de exposición y el enfoque teórico que les subyace.

Sin embargo, en el título de uno de sus artículos, David C. Colander (n. 1947) define a la enseñanza de la ciencia económica como un arte que enfrenta muchas complejidades al momento de transmitirla a los estudiantes; especialmente, es preciso cuidar tanto la forma de enseñar y la tecnología disponible para ello, como el contenido y orientación de aquello que se enseña a las nuevas generaciones de economistas. Esto último — conjuntamente a la transmisión de la emotividad despertada por lo que se enseña y la precaución respecto del hecho de que los modelos solo poseen cierto grado de verdad y son útiles en ciertos casos y en otros no- es lo que determina si un docente es bueno o no, así como el esfuerzo que haga en la investigación sobre la enseñanza de la economía — marginada y despreciada por muchos economistas - para traducir las contribuciones del análisis económico en debates accesibles 0 digeribles y en modelos comprensibles para los estudiantes y útiles para el diseño de políticas; siendo pertinente en este proceso la necesidad de asumir al método lógico científico no como verdad sino como narrativa, y hacer del análisis económico un motor de descubrimiento de verdades concretas y no solo un procesamiento de información general (Colander, 2004).

Pese a esta ingeniosa propuesta pedagógica para la enseñanza de la ciencia económica, fieles y obedientes como son a la idea de ofertar lo que se demanda, algunos economistas señalan que los estudiantes de licenciatura no suelen mostrar interés en la teoría y los fundamentos científicos del análisis económico, sino que se inclinan más por incidir en las políticas públicas y por la perspectiva ingenieril de la profesión de economista (Mankiw, 2011). En ese sentido, la formación de las jóvenes generaciones en las escuelas de ciencias económicas y empresariales donde predo- 
mina la teoría económica neoclásica no incluye el estudio del pensamiento económico ni las obras de los autores clásicos de la disciplina (Richard Cantillon, Adam Smith, David Ricardo, John Stuart Mill, Karl Marx, Alfred Marshall, Joseph A. Schumpeter, John Maynard Keynes, entre otros), al tiempo que se omite la relevancia del análisis histórico y geográfico para comprender el comportamiento de los fenómenos económicos, así como de la reflexión filosófica, ética y metodológica para asimilar los fundamentos epistemológicos y ontológicos de la construcción del conocimiento científico, situación que inhibe las posibilidades de emprender una investigación de corte interdisciplinario.

Ante esta necesidad, se experimenta en la enseñanza una excesiva especialización que impone el ejercicio de deducción al trabajo empírico. Esta marcada especialización se presenta tanto en el oficio de la investigación como en el proceso de enseñanza/aprendizaje, hasta el extremo de hacer de la economía un compartimento estanco que a su vez tiende a fragmentar el análisis económico y a deformar el conocimiento de la realidad social. La formación del economista convencional experimenta serias limitaciones y no cuenta con habilidades para comprender la naturaleza de las instituciones y de las decisiones y procesos políticos; la dinámica de la historia económica, social y política que estudia el cambio de las sociedades y no las tendencias al equilibrio o el retorno de una situación a un supuesto estado inicial; la relevancia del espacio geográfico y el territorio en la estructuración y especificidades del proceso económico; los orígenes, continuidades y rupturas de la historia del pensamiento económico y las aportaciones contemporáneas de la literatura económica; los alcances y limitaciones de los datos cuantitativos y cualitativos; y aceptar o tolerar otros enfoques teóricos, disciplinarios 0 interdisciplinarios complementarios 0 alternativos a la teoría económica hegemónica y que son rechazados, sin más, por considerarse fútiles y faltos de rigor, objetividad y formalización matemática. De igual manera, en aras de privile- giar el rigor de la abstracción modelizadora, este economista no logra desarrollar la observación de problemas reales y concretos inscritos en procesos históricos más amplios.

Por si fuera poco, la teoría económica predictiva, objetivista y formalizadora no distingue entre predicción (probabilidades y creencias) y explicación; entre verdad y validez; entre el todo y la suma de las partes; entre enunciados tautológicos y deducciones de axiomas; entre el método y la realidad social; entre el individuo calculador y el conjunto de la naturaleza 0 esencia del ser humano; entre producción, intercambio y consumo; entre el mercado y una entidad sobrenatural; 0 entre la temporalidad de los hechos económicos y la eternidad sin mirada al pasado. Aún más, se esfuerza en camuflar los enunciados normativos con el análisis económico dotado de pretensiones de razonamiento científico y hace de los enunciados positivos caminos que en sí poseen prescripciones; subsume las relaciones empíricas al aislado hecho empírico en sí que es subsumido por el ceteris paribus; explica las relaciones sociales a partir de las elecciones de los individuos racionales —imaginariamente idénticos y solo diferentes por sus gustos y preferencias y por la dotación de recursos inicialesque, como sumatoria, forman la sociedad; encubre las relaciones de poder con el afán maximizador y desbordado del Robinson Crusoe; hace del capitalismo un sistema de equilibrio general competitivo —o si acaso de equilibrio parcial — movido por las expectativas racionales (asumidas como dadas pero jamás explicadas en su esencia y orígenes); y se obsesiona por seguir a los físicos en la búsqueda de fuerzas del mercado que tienden al equilibrio y la vuelta de un hecho económico a un aparente estado inicial, lo cual es incongruente si quedamos que el individuo racional hará lo que sea por maximizar sus beneficios. Todo lo cual no es exclusivo del oficio de investigación del economista, sino que se extiende también a su proceso de enseñanza/aprendizaje y al ejercicio profesional y la toma decisiones donde hace acto de presencia e influye, directa e indirecta- 
mente, en el diseño y ejercicio de la política económica. De ahí la apremiante necesidad de incluir cursos y seminarios de epistemología, lógica, ética, teoría política y sociológica, geografía e historia en los planes de estudios que forman a los profesionistas de la economía; ello asumiendo el carácter interdependiente y articulado de fenómenos que suelen estudiarse de manera aislada.

Hace más de ocho décadas, John Maynard Keynes, en apego a su idea de que la economía es un método 0 una técnica del pensamiento para abordar los hechos económicos y llegar a conclusiones, sugería combinar - con base en la imaginación intuitiva y el criterio práctico — varios talentos para dominar la ciencia económica, tales como el razonamiento matemático para interpretar los símbolos y explicarlos con palabras; el análisis histórico para estudiar el presente a partir del pasado y apostando al futuro; la vocación de estadista para tomar decisiones de manera desinteresada y con los pies firmes en la tierra; y la reflexión filosófica para abordar el conjunto de la naturaleza del hombre y de sus instituciones (Keynes, 1933). La excesiva especialización y la preeminencia de un solo lenguaje para representar la realidad terminaron por alejar la formación del economista de esta pretensión keynesiana e hizo de la economía una ciencia autista.

\section{Consideraciones finales}

Más que pronunciarnos a favor 0 en contra de la metodología que prevalece en el enfoque hegemónico de la ciencia económica y más que demeritar 0 desacreditar a esta disciplina por las limitaciones ontológicas y epistemológicas que le son propias, lo que se pretendió a lo largo del presente escrito fue acercarnos a la comprensión del sentido en que se realiza la construcción de conocimiento científico en la economía, ponderando sus contribuciones (la comprensión, de manera agregada, de la lógica calculadora del individuo), alcances y limitaciones. Al tiempo que reconocemos lo fascinante e intenso que nos resulta el recorrido por la historia del pensamiento económico, reconocemos también la necesidad de darle un lugar primordial a la crítica constructiva y constante hecha desde adentro (claros ejemplos de ello es el llamado movimiento postautista de economía y aquellos autores que se pronuncian por una economía sin Robinson Crusoe) y desde afuera de la ciencia económica, pues este ejercicio metateórico puede ayudar a asumir a las crisis teóricas como una experiencia incesante, saludable, permanente y necesaria para dinamizar, revitalizar, renovar y recrear el conocimiento de lo social humano; y, así, enriquecer, sensibilizar, ampliar y revolucionar a un oficio de la investigación y a un proceso de enseñanza/aprendizaje no exentos de la inadecuación histórica.

Incluso, en su momento, destacados economistas que alcanzaron la presidencia de la American Economic Association señalaron argumentos como los siguientes: la economía -y especialmente la econometría - es la mecánica celeste de un mundo inexistente (Boulding, 1969); «prevalece la preocupación por la realidades imaginarias e hipotéticas y no por la realidad observable» (Leontief, W., 1970). Por su parte, otros economistas se aventuran a señalar que la economía moderna, ataviada de su lenguaje matemático y de modelos que no son de fiar, es una forma de daño o lesión cerebral [Hazel Henderson (n. 1933)] o que se experimenta un subdesarrollo de la economía como ciencia (Berzosa Alonso-Martínez, 2006). Sin embargo, aunque en sus orígenes el análisis económico sufrió de calificativos reaccionarios como los esgrimidos por Thomas Carlyle (1795-1881) y John Ruskin (18191900), quienes señalaron en distintos momentos que la economía es una ciencia lúgubre (dismal science), triste, desolada, abyecta, funesta y miserable (Carlyle, 1849); una filosofía para cerdos, una materia sórdida, mezquina y carente de valor (Ruskin, 1862); ya hacia finales del siglo XIX — bajo la influencia de la investigación termodinámica, sus leyes y su énfasis en la energía- y en aras de alcanzar un prestigio profesional alejado de la 
influencia de la ideología, el economista comenzó a desplegar una especie de envidia por la física (calificativo estipulado por Mirowski, 1997/1998) hasta pretender entronizarse, a lo largo del siglo XX y los primeros lustros del siglo XXI, por encima del resto de las ciencias sociales mediante, según se dice, una marcada arrogancia intelectual (Naím, 2006) y un complejo de fraudulenta superioridad intelectual (Naím, 2015) combinadas — por el desconocimiento de sus propias limitaciones - con un sentimiento de inferioridad y envidia respecto de los matemáticos y los físicos, aunque desconociendo las limitaciones de estos (Streeten, 2002). Pese a todo ello, de cara a la falta de previsión y predicción de la crisis económico/financiera de 2008-2009, al interior de la teoría económica hegemónica se preguntan: ¿cómo pudieron equivocarse tanto los economistas? (véase Krugman, 2009).

En el fondo de estas incisivas y hasta mordaces críticas está el hecho de remarcar la incapacidad, las cegueras y la insensibilidad de la ciencia economía hegemónica para prevenir y contribuir a las posibles soluciones y alternativas relacionadas con los acuciantes problemas de la economía mundial y de las sociedades nacionales.

Es de destacar también que la investigación cuantitativa y la representación matemática son relevantes, tanto el enseñarlas y conocerlas, como el ejercerlas; pero es necesario colocarlas en su justa dimensión y comprender sus limitaciones como lenguaje en el marco más amplio de las cegueras de la teoría económica neoclásica, y especialmente - someterlas a las exigencias de los diálogos interdisciplinarios y a la necesidad de cultivar la apertura y sensibilidad en el economista convencional.

Aunado a todo lo anterior, las relaciones de poder, las vanidades, el estatus y prestigio profesional, y el mayor pedigrí de unas disciplinas respecto de otras (al refugiarse en la formalización matemática, el economista resguardó su estatus y prestigio profesional) llevan a inhibir las pretensiones de colocar a la interdisciplinariedad en el centro de la docencia y la investigación. Los economistas, muchas veces, desean llevar la voz cantante y ser quienes formulan las preguntas principales e imponer sus supuestos, conceptos, categorías, métodos y técnicas (tal como en el llamado imperialismo económico de Gary Becker y otros, que de lejos no es ni multidisciplinariedad); ante ello, es pertinente anteponer el descentramiento disciplinario y en los estudios formular conceptos y categorías interdisciplinarias (un ejercicio al respecto se observa en Enríquez Pérez et ál., 2015, en el cual convergen un geógrafo, una diseñadora gráfica, una ingeniera civil, una internacionalista, un médico y un sociólogo/economista).

Más aún, la visión estrecha y compartimentalizada del economista convencional puede atribuirse a las enormes masas de conocimientos y al dominio de la excesiva especialización de la fuerza de trabajo calificada que impone y demanda la empresa privada y su régimen corporativo extendido a la gestión y administración del sector público y a los organismos internacionales; a ello se ven obligadas a responder las universidades tanto con la formación de cuadros de jóvenes generaciones dotados de aptitudes muy reducidas y parceladas, como con la pérdida de autonomía en la generación de nuevos conocimientos (investigación), que en no pocas ocasiones son por «encargo» (nos referimos a la gran cantidad de académicos dedicados a labores de asesoría y consultoría). Todo ello va en detrimento de la teorización de la totalidad, del ejercicio del pensamiento crítico y de la investigación interdisciplinaria.

Especialmente, al interior de las ciencias sociales, el pensamiento y análisis histórico ayudaría a la relación interdisciplinaria entre las ciencias económicas y las ciencias políticas, resaltando la relevancia recíproca que unas tienen respecto de las otras, tal como se manifiesta en la teorización propia de la sociología económica.

Es necesario trascender el supuesto o la hipótesis de la racionalidad maximizadora de utilidades 0 beneficios como fundamento que explica todas las conductas humanas. Siguiendo a Edgar Morin (n. 
1921), el ser humano es unidual, es biológico, pero también es cultural y, a su vez, es un homo sapiens y un homo demens que lo mismo es movido por la razón, el afecto, el amor, el impulso, el mito, la magia, la religión y el delirio; esto es, el homo faber (trabajador) es un homo ludens que juega, el homo empiricus es también un homo imaginarius, el homo economicus es a su modo un homo consumans que dilapida, y el homo prosaicus es también un homo poeticus que ama y se extasía (Morin, 1999).

Finalmente, cabe preguntarse: ¿cómo estudiar prácticas económicas que no sólo responden a criterios materiales? ¿De qué manera estudiar fenómenos económicos como los propios de las prácticas del buen vivir 0 de aquellas comunidades que no privilegian la producción de bienes materiales más allá de lo necesario para sus parámetros de subsistencia y reproducción social? ¿Cómo estu- diar al proceso económico y al mercado desde una perspectiva institucionalista y cultural? Interrogarse esto es pertinente de cara a la proliferación de indicadores como el PIB, el PIB per cápita, el Índice de Desarrollo Humano, entre otros, que suelen ser engañosos, simples promedios, encubrir realidades más vastas, y limitados para llegar a la esencia de los hechos económicos o para comprender fenómenos sociales multidimensionales como la desigualdad social e internacional. Estas y otras preguntas y reflexiones son pertinentes de cara a la entronización del dogmatismo y a la resignación teórica que asfixian el pensamiento utópico e inhiben la investigación interdisciplinaria; ejercicios tan necesarios para comprender y trascender la contemporánea crisis sistémica y estructural del capitalismo como modo de producción y como proceso (des)civilizatorio.

\section{Referencias bibliográficas}

- Aristóteles [350 a. C. (1985)]. Ética nicomáquea - Ética eudemia. Madrid: Gredos.

- Arrizabalo Montoro, X. (2014). Capitalismo y economía mundial. Bases teóricas y análisis empírico para la comprensión de los problemas económicos del siglo XXI. Madrid: Instituto Marxista de Economía, ARCIS y Universidad de Concepción.

- Ayala Espino, J. (1999). Instituciones y economía. Una introducción al neoinstitucionalismo económico. México: Fondo de Cultura Económica.

- Becker, G.S. (1976). The economic approach to human behavior. Chicago: The University of Chicago Press.

- Berzosa Alonso-Martínez, C. (2006). Economía del subdesarrollo y subdesarrollo de la economía.
Principios: estudios de economía política, 4, 5-22.

- Boland, L.A. (1997). Critical economic methodology. A personal odyssey. London and New York: Routledge.

- Boulding, K.E. (1969). Economics as moral science. The American Economic Review, 59(1), 1-12.

- Bourdieu, P. [2000 (2002)]. Las estructuras sociales de la economía. Buenos Aires: Manantial.

- Carlyle, Th. (1849). Occasional discourse on the negro question. Fraser's Magazine for Town and Country, XL, 530-531.

- Colander, D.C. (2004). The art of teaching economics. International Review of Economics Education, 3(1), 63-76.
- Cue Mancera, A. (2003). Samuelson y la enseñanza de la teoría económica. Análisis Económico, XVIII(38), 297-324.

- Dobb, M. [1973 (1976)]. Teorías del valor y de la distribución desde Adam Smith. Ideología y teoría económica. Buenos Aires: Siglo XXI Editores.

- Engels, F. [1859 (2000)]. La contribución a la crítica de la economía política de Karl Marx. En Karl Marx, Contribución a la crítica de la economía política (6ta. Edición en español), (pp. 333-343). México: Siglo XXI Editores.

- - [1878 (1968)]. AntiDühring. La subversión de la ciencia por el señor Eugen Dühring (2da. Edición en español). México: Grijalbo. 
- Enríquez Pérez, I. (2008a). El modelo económico de Adam Smith y el papel que le asigna a las instituciones y al Estado en la economía. Laissez-Faire, 28-29, 18-28.

- - (2008b). La construcción del pensamiento científico en las ciencias físico/naturales y en la economía. Notas para desentrañar la naturaleza epistemológica de las ciencias económicas. Economía, gestión y desarrollo, 6, 39-77.

(2014). Las innovaciones organizacionales y tecnológicas en la industria aeroespacial: un análisis de su comportamiento a la luz de la comparabilidad internacional. En Alfonso Bouzas Ortiz (coord.), Globalización y trabajo. Cambios tecnológicos, migración y nueva regulación laboral (pp. 7-20). México: UNAM.

- Enríquez Pérez, I., Ricárdez Cabrera, M.M., Bustos Cardona, L.0., Martínez, A.M., López Gamboa, F.S., y Durán Vázquez, A. (2015, mayoagosto). Universidadanía: la construcción socioespacial y simbólica del hábitat universitario y su concepción como sistema complejo. INTERdisciplina, 3(6), 113-141.

- Fischer, S., Dornbusch, R., y Schmalensee, R. [1987 (1994)]. Economía (2da. Edición en Español). España: McGraw-Hill Interamericana.

- Fontela Montes, E. (1990). Fundamentos históricos de la economía aplicada. Una visión personal. Economistas, 8(43), 52-57.

- Friedman, M. [1953 (1967)]. Ensayos sobre economía positiva. Madrid: Gredos.

- Graue Russek, A.L. (2009). Fundamentos de economía. México: Pearson/Prentice Hall.

- Gill, L. [1996 (2002)]. Fundamentos y límites del capitalismo. Madrid: Trotta.
- Hahn, F.H. (1994). An intellectual retrospect. Banco Nazionale del Livoro Quarterly Review, 47(190), 245-258.

- Jenofonte [362 a. de c. (1993)]. Económico (Oікоvоцико́s). Маdrid: Gredos.

- Jevons, W.S. [1871 (1970)]. Theory of political economy. London: Penguin Books.

- Keynes, Jh.M. (1931). Essays in persuasion. London: MacMillan and Co. - — [1933 (1963)]. Essays in biography. New York: W.W. Norton \& company, Inc.

- Krugman, P. (2009, primer semestre). ¿Cómo pudieron equivocarse tanto los economistas?. Apuntes del CENES, XXVIII(47), 185-194.

- Krugman, P., Wells, R., y Graddy, K. [2011 (2012)]. Fundamentos de economía (2da. Edición en español). México: Reverté.

- Leontieff, W. [1970 (1971, marzo)]. Discurso presidencial dirigido a la reunión NNo. 83 de la Asociación American de Economía, Detroit, Michigan, 29 de diciembre de 1970. The American Economic Review, 1-7.

- Mankiw, N.G. (2007, abril-junio). El macroeconomista como científico y como ingeniero. Desarrollo económico, 47(185), 3-23.

- — [2011 (2012)]. Principios de economía. México: Cengage Learning.

- Marshall, A. [1890 (1957)]. Principios de economía. Un tratado de introducción (1era. Edición en español). España: Ediciones Aguilar. [1901 (1925)]. Letter to Arthur Lyon Bowley, 3 march 1901. En Arthur C. Pigou (ed.), Memorials of Alfred Marshall. London: MacMillan and. Co.
Marx, K. [1857 (1989)]. Introducción general a la crítica de la economía política/1857 (21era. Edición en español). México: Siglo XXI Editores. - —— [1867 (2008)]. El capital. Crítica de la economía política, Tomo I/Nolumen I (28va. Edición en español). México: Siglo XXI Editores.

- Marx, K. y Engels, F. [1846 (1974)]. La ideología alemana (5ta. Edición en español). Barcelona: Ediciones Grijalbo y Ediciones Pueblos Unidos. - Mill, J.S. [1836 (2007)]. On the definition of political economy, and on the method of philosophical investigation in that science. En Daniel M. Hausman (ed.), The philosophy of economics. An anthology (2da. Edición), (pp. 52-68). Cambridge: Cambridge University Press.

-—_ [1844 (1997)]. Ensayos sobre algunas cuestiones disputadas en economía política (1era Edición en español). Madrid: Alianza Editorial.

- Mirowski, Ph. (1997/1998, diciembre-enero). iSufren los economistas de envidia a la física?. Economía Informa, 263, 21-28.

- Mochón Morcillo, F. (2006). Principios de economía. México: McGraw Hill/Interamericana.

- Morin, E. (1999). Los siete saberes necesarios para la educación del futuro (1era. Edición). París: UNESCO. - Naím, M. (21 de febrero 2006). La arrogancia de los economistas. El país, p. 3. Madrid.

- _- (29 de marzo 2015). La fraudulenta superioridad de los economistas. La Tercera, p. 41. Santiago de Chile.

- Platón [380 a.C. (1986)]. República. Diálogos IV. Madrid: Gredos.

- Pigou, A.C. [1920 (1932)]. The economics of welfare. London: MacMillan and. Co. 
- Popper, K.R. [1934 (1962)]. La lógica de la investigación científica. Madrid: Tecnos.

- — [1963 (1983)]. Conjeturas y refutaciones. El desarrollo del conocimiento científico. Barcelona: Paidós.

- Ricardo, D. [1817 (1994)]. Principios de economía política y tributación. México: FCE.

- Robbins, L. [1932 (1945)]. An essay on the nature and significance of economic science (2da. Edición). London: MacMillan and. Co.

- — [1981 (1982), eneromarzo]. La economía y la economía política. El Trimestre Económico, XLIX(193), 189-205.

- Ruskin, J. [1862 (2014)]. A este último: cuatro ensayos sobre los principios de la economía política (1era. Edición en español). España: Alhulia Editorial.

- Sáez Lozano, J.L. (1998). La economía como ciencia aplicada. Estudios Públicos, 69, 299-317.

- Samuelson, P.A. [1947 (1977)]. Fundamentos de análisis económico (4ta. Edición en español). Buenos Aires: Librería el Ateneo.

- Samuelson, P.A. (1948). Economics. Estados unidos: Mc Graw Hill.
- Samuelson, P.A., y Nordhaus, W.D. [1985 (2006)]. Economía. Madrid: McGraw Hill.

- Schumpeter, J.A. [1954 (1971)]. Historia del análisis económico. España: Ariel.

- Smith, A. [1776 (2000)]. Investigación sobre la naturaleza y causas de la riqueza de las naciones. México: FCE.

- Streeten, P. (2002). What's wrong with contemporary economics?. Interdisciplinary Science Review, 27(1), 13-24.

- Zamora, F. [1953 (1984)]. Tratado de teoría económica. México: FCE.

\section{Registro bibliográfico}

Enríquez Pérez, I. (2016). Contrapuntos en torno al concepto, metodología y enseñanza de la economía: notas críticas para comprender la construcción y transmisión del conocimiento en las ciencias económicas. Revista Ciencias Económicas, 13(02), 21-48. 